\title{
A Dilemma in Management of Intrauterine Death in Mother with Major Placenta Previa
}

\author{
Rima Anggrena D (凶), Yulianty A, Nor Azlin MI \\ Department of Obstetrics \& Gynaecology, Faculty of Medicine, Universiti Kebangsaan Malaysia Medical \\ Centre, Jalan Yaacob Latif, Bandar Tun Razak, 56000 Cheras, Kuala Lumpur, Malaysia.
}

\begin{abstract}
Placenta previa is a condition when the placental tissue extends over the internal cervical os. It is associated with maternal and fetal morbidity and mortality. With intrauterine death, the mode of delivery will be more difficult to decide. Here, we report a case of 30 years old G3P2 with placenta previa major diagnosed with intrauterine death at 29 weeks gestation who was managed conservatively and delivered vaginally with minimal complication. A good patient selection and thorough counseling, patient with placenta previa major and intrauterine death still can be safely delivered vaginally.
\end{abstract}

Keywords: $\quad$ Coagulopathy, hemorrhage, intrauterine death, placenta previa, vaginal birth

\section{Correspondence:}

Rima Anggrena Dasrilsyah. Department of Obstetrics \& Gynaecology, Faculty of Medicine, Universiti Kebangsaan Malaysia Medical Centre, Jalan Yaacob Latif, Bandar Tun Razak, 56000 Cheras, Kuala Lumpur, Malaysia. Tel: +603-91455949 Fax: +603 91456672 E-mail: rimadasril@yahoo.com

\section{Introduction}

Placenta previa is a condition when the placental tissue extends over the internal cervical os. Its incidence ranged from 3.5-4.6 per 1000 birth and contributed by combination of factors due to rising number of caesarian sections and increasing maternal age $(1,2,3)$. Placenta previa is associated with maternal and fetal morbidity and mortality. The management is complicated, especially when deals with intrauterine death. It is indeed a challenge in decision making of its management for the best interest of patient and the unborn fetus.

\section{Case Report}

A 30-years-old housewife, gravida 3 para 2 at 33 weeks gestation with underlying gestational diabetes mellitus on diet modification with history of two spontaneous vertex deliveries, was diagnosed with placenta previa major at 28 weeks period of amenorrhea. She never had any per vaginal bleeding or abdominal pain. Unfortunately, at 29 weeks gestation, she was diagnosed with intrauterine death and opted for conservative management with weekly full blood count and coagulation profile.

She remained well until 33 weeks gestation when she presented to emergency department with increased vaginal bleeding. On assessment, she was pale, her blood pressure was $132 / 74 \mathrm{mmHg}$, pulse rate of 114 beats/minute and afebrile. Abdominal examination was soft and non-tender, uterus of 28 weeks size, singleton, longitudinal lie and cephalic presentation five fifth palpable. Speculum examination showed blood clots with cervical os open. Vaginal examination revealed cervical os of $3 \mathrm{~cm}$ with bulging membrane and placental edge felt.

She was admitted and given epidural. The labour was augmented and cervical os was fully dilated after three hours. She was encouraged to bear down after artificial rupture of membrane. However, as anticipated, there was no descend of fetal head due to placenta. In view of increased vaginal bleeding with clots, attending specialist decided to remove the placenta manually 
followed by delivery of the fetus. The placenta was removed in one piece and no true knot noted at the umbilical cord. Intravenous carbetocin was given and uterus contracted 20 weeks size. Perineum was intact and no active bleeding. The estimated blood loss was $1000 \mathrm{ml}$.

Patient delivered a macerated baby girl weighing $1.42 \mathrm{~kg}$. There was no gross abnormality seen. The histopathology result of the placenta sent showed uteroplacental insufficiency with placenta infarction and atheroma. There was no growth in placental swab culture.

\section{Discussion}

There are only small numbers of reported cases of intrauterine death with placenta previa. These patients were managed differently depending on case to case basis. To date there is still no general consensus the best way to manage such cases. However, in general, placenta previa with fetal death can be managed in 3 main ways.

Approximately about $85 \%$ women with intrauterine death will deliver spontaneously within 3 weeks of diagnosis (4). Theoretically, uteroplacental blood perfusion will decrease causing placental atrophy. Thus, it can reduce the blood loss during vaginal delivery (5). Unfortunately, expectant management could have disadvantages as $10 \%$ of patient may develop DIVC within one month after fetal demise (6). Therefore, women who delay in labour for periods longer than 48 hours should be advised to have DIVC testing twice weekly (2). Risk of intrauterine infection will also increase in time. Furthermore, keeping dead baby can lead to psychological stress to the mother. A Sweedish study in 1996 shows in interval of 24 hours or more from the diagnosis of death in utero to start of labour, there is increase of moderately severe anxiety or worse (7).

If the patient has not been delivered within 2 or 3 weeks, induction of labour is recommended as placental atrophy will be slowing down thus the chance of spontaneous labour will be low. Furthermore, the risk of coagulopathy and infection will rise (8). By inducing labour in intrauterine death, approximately about $90 \%$ of women can achieve vaginal birth within 24 hours (9). RCOG guideline (2) suggests using mifepristone and prostaglandin as first line intervention in unscarred uterus. Meanwhile, NICE (4) endorses misoprostol for usage of induction of labour for those patients. In a case reported by Taka et al, attempt using mechanical induction i.e. laminaria leads to massive hemorrhage as cervical dilation without effective uterine contraction results in partial placental separation in the absence of compression by fetal membrane or fetal part (5). Thus, laminaria is not recommended to be used in case of placenta previa. In fact, no mechanical cervical dilation was used before in labour induction in previous other cases of placenta previa with fetal demise $(5,8,10)$.

The last option will be surgical termination. The first method is by dilatation and evacuation (D\&E). It is a safe procedure with an experienced surgeon and can be done until about 24 weeks of gestation (8). Second option is by hysterotomy or caesarian section. A study shows pregnant women with intrauterine death who chose for induction of labour has $15.6 \%$ accumulated risk of undergoing caesarian section in the first 48 hours of labour management (11). There are several known risk associated with caesarean section, i.e. operative morbidity and mortality, increase risk of placenta abnormalities such as placenta accrete and risk of uterine rupture in subsequent pregnancy. However, in some circumstances, caesarean section is the best option for patient safety. For instance, in the case of placenta abruption with coagulopathy, cephalopelvic disproportion or failed induction (11). Based on previous reports published before, it is suggested that vaginal delivery is relatively a safe option for second and third trimester fetal demise, thus caesarean section should be reserved as the last resort (5). Therefore, it was decided that our patient be managed in the aim of vaginal delivery after a thorough discussion with patient and husband. Fortunately, in our case, patient did not developed coagulopathy and went to spontaneous labour. However, intrapartum bleeding was significant despite of fetal demise, thus placenta need to be evacuated before the fetus.

\section{Conclusion}

Management of placenta previa with intrauterine death could be a predicament to the obstetrician. Thus, thorough discussion with the patient and family is important to maximize the benefit to the patient as each option has its own benefits.

\section{References}

1. Faiz AS, Ananth CV. Etiology and risk factors for placenta previa: an overview and metaanalysis of observational study. J Matern Fetal Neonatal Med. 2003; 13(3): 175-90.

2. Royal College of Obstetricians and Gynaecologists. Late intrauterine fetal death and 
stillbirth (Greentop Guideline No 55) RCOG: London, 2010; 1-33.

3. Tan KC, Chuah CY, Fong KY, Phang SL, Nor Azlin MI. Placenta Praevia: Preach and Perception. Medicine \& Health 2007; 2(2): 13945.

4. National Collaborating Centre for Women's and Children's Health (UK). NICE Clinical guideline no 70 - Induction of labour. London: RCOG Press, 2008 https://www.nice.org.uk/guidance/cg70 Last accessed on 3 January 2017

5. Taki M, Sato Y, Kakui K, Tatsumi K, Fujiwara $\mathrm{H}$, Konishi I. Management of fetal death with placenta previa. J Matern Fetal Neonatal Med. 2012; 25(2): 196-9.

6. Parasnis H, Raje B, Hinduja IN. Relevance of plasma fibrinogen estimation in obstetric complications. J Postgrad Med 1992; 38(4): 183-5.

7. Rådestad I, Steineck G, Nordin C, Sjögren B. Psychological complications after stillbirthinfluence of memories and immediate management: population based study. BMJ. 1996; 312(7045): 1505-8.

8. van der Ploeg JM, Schutte JM, Pelinck MJ, Huisjes AJ, van Roosmalen J, de Vries JI. Management of fetal death after 20 weeks of gestation complicated by placenta previa. J Matern Fetal Neonatal Med 2007; 20(3): 267-9.

9. Wagaarachchi PT, Ashok PW, Narvekar NN, Smith NC, Templeton A. Medical management of late intrauterine death using combination of mifepristone and misoprostol. BJOG 2002; 109(4): 443-7.

10. Sillender M, Krishnamurthy S. Medical management of second trimester fetal death complicated by a complete placenta previa. J Obstet Gynaecol 2000; 20(5): 537-8.

11. do Nascimento MI, Cunha Ade A, Oliveira SR. Clinical management of induction of labor in intrauterine fetal death: evaluation of incidence of cesarian section and related conditions. Rev Bras Epidemiol 2014; 17(1): 203-16. 